\title{
CORRECTION
}

\section{Correction: Outcome of haematology patients admitted to intensive care in a tertiary centre: primary heamtological diagnosis, recent chemotherapy and bone marrow transplantation are not associated with outcome}

\author{
Ricardo Jose, Isla MacDonald, Paul Pfeffer, Steve Shaw and Banwari Agarwal
}

See related abstract by José et al., http://ccforum.com/content/15/S1/P497

After publication of their conference abstract [1], the authors found the following error:

In the 'Results' section, "Of the 97 patients, NHL (30.9\%) and AML (26.8\%) accounted for most haematological diagnoses. A total $24.7 \%$ were post-BMT, and $36.1 \%$ had chemotherapy within a month of admission or on the ICU", the proportion of patients with NHL should be $28 \%$ and for those post-BMT it should be $28 \%$.

\section{Competing interests}

The authors declare that they have no competing interests.

Published: 19 July 2012
Reference

1. José R, McDonald I, Pfeffer P, Shaw S, Agarwal B: Outcome of haematology patients admitted to intensive care in a tertiary centre: primary haematological diagnosis, recent chemotherapy and bone marrow transplantation are not associated with outcome. Crit Care 2011, 15(Suppl 1):P497. 